\title{
Expansion of mesenchymal adipose-tissue derived stem cells in a stirred single-use bioreactor under low-serum conditions
}

\author{
Carmen Schirmaier ${ }^{1 *}$, Stephan C Kaiser ${ }^{1}$, Valentin Jossen ${ }^{1}$, Silke Brill ${ }^{2}$, Frank Jüngerkes ${ }^{2}$, Christian van den Bos ${ }^{2}$, \\ Dieter Eibl ${ }^{1}$, Regine Eibl ${ }^{1}$
}

From 23rd European Society for Animal Cell Technology (ESACT) Meeting: Better Cells for Better Health Lille, France. 23-26 June 2013

\section{Background}

The need for human mesenchymal stem cells (hMSCs) has increased enormously in recent years due to their important therapeutic potential. Efficient cell expansion is essential to providing clinically relevant cell numbers. Such cell quantities can be manufactured by means of scalable microcarrier (MC)-supported cultivations in stirred single-use bioreactors.

\section{Materials and methods}

Preliminary tests in disposable-spinners $(100 \mathrm{~mL}$ culture volume, Corning) were used to determine two suitable media and MC-types for serum reduced expansions $(<10 \%)$ of human adipose tissue-derived stem cells (hADSCs; passage 2, Lonza). Using such optimized media-MC-combinations, hADSCs expanded 30 to 40fold, which compares well with expansion rates in planar culture. Based on computational fluid dynamics simulations and suspension analyses in spinners [1], optimal operating parameters were determined in a BIOSTAT ${ }^{\circledR}$ UniVessel $^{\mathbb{B}}$ SU 2 L (2 L culture volume, Sartorius Stedim Biotech).

\section{Results}

In subsequent batch tests with the BIOSTAT UniVessel ${ }^{\circledR}$ SU 2 L, expansion rates of between 30 and 40-fold were reached and up to $4.4 \cdot 10^{8}$ cells with a cell viability exceeding $98 \%$ were harvested. Flow cytometry tests demonstrated typical marker profiles following cell

\footnotetext{
* Correspondence: *carmen.schirmaier@zhaw.ch

'Zurich University of Applied Sciences, Institute of Biotechnology, Biochemical Engineering and Cell Cultivation Technique, 8820 Wädenswil, Switzerland

Full list of author information is available at the end of the article
}

expansion and harvest. A 40-fold expansion rate delivered a total of $1 \cdot 10^{10}$ cells in a first cultivation with the BIOSTAT ${ }^{\circledR}$ CultiBag STR $50 \mathrm{~L}$ (35 L culture volume, Sartorius Stedim Biotech).

\section{Conclusions}

In summary, the foundations for successfully expanding therapeutic stem cells in truly scalable systems have been laid. Strategies ensuring expansion rates between 60 and 70 -fold and, thus, generating cell amounts over $10^{10}$ are now in preparation.

\section{Acknowledgements}

This work is part of the project "Development of a technology platform for a scalable production of therapeutically relevant stem cells" (No. 12893.1 VOUCH-LS). It is supported by the Commission for Technology and Innovation (CTI, Switzerland). The authors would like to thank the CTI for partially financing the investigations presented.

\section{Authors' details}

'Zurich University of Applied Sciences, Institute of Biotechnology, Biochemical Engineering and Cell Cultivation Technique, 8820 Wädenswil, Switzerland. 'Lonza Cologne GmbH, 50829 Cologne, Germany.

Published: 4 December 2013

Reference

1. Kaiser S C, Jossen V, Schirmaier C, Eibl D, Brill S, van den Bos C, Eibl R: Investigations of fluid flow and cell proliferation of mesenchymal adipose-derived stem cells in small-scale, stirred, single-use bioreactors. Chem Ing Tech 2013, 85:95-102.

\section{doi:10.1186/1753-6561-7-S6-P2}

Cite this article as: Schirmaier et al:: Expansion of mesenchymal adipose-tissue derived stem cells in a stirred single-use bioreactor under low-serum conditions. BMC Proceedings 2013 7(Suppl 6):P2. 